\title{
Visualized Analysis of China's Land Transfer and Scale Research Based on Quantification and Atlas
}

\author{
Dongmei Liang ${ }^{1 * *}$
}

\author{
${ }^{1}$ School of Public Affairs and Administration, University of Electronic Science and Technology of China, Chengdu, \\ Sichuan 611713, China \\ *Corresponding author. Email: ldm1210@std.uestc.edu.cn
}

\begin{abstract}
The use of CiteSpace software to analyze the CNKI (Chinese National Knowledge Internet) database is not limited. The research literature of "Land Scale" in 2020 shows that after rapid growth, the number of publications has entered a stable stage, and a number of major research institutions such as Sun Yatsen University and the Rural Economic Research Center of the Ministry of Agriculture have been formed. A number of highly productive authors such as Huang Haitang, Wu Lianglin, and Zhou Huijie are gradually taking shape. Research shows that there is little horizontal cooperation between research institutions and authors. At present, Chinese research on land transfer and scale is mainly concentrated in four hot areas: land transfer and scale subjects, business methods and models, meaning, and summarizing local experiences. With land transfer, research institutions and scholars should stand at the height of think tank construction, explore land circulation and large-scale meso-level research, concentrate on the theoretical interpretation and practical exploration of land circulation, and carry out theoretical innovation and institutional innovation to provide scientific reference basis for national decision-making.
\end{abstract}

Keywords: land scale, quantitative analysis, CiteSpace

\section{INTRODUCTION}

The 2020 Rural Land Contract Law of the People's Republic of China clarifies the basic principle of the separation of the three rights of agricultural land, that is, the separation of land ownership, contracting rights, and management rights. The basic attributes of collective ownership remain unchanged, the contracting rights are stabilized, the contract period is extended, and the transfer of land management rights is encouraged. This is also the direction of a new round of agricultural reform.

Land is the most important resource and production factor in rural areas. With the development of industrialization, informatization, urbanization, and agricultural modernization, the state is required to promote land transfer and scale operations. With the changes in the degree of integration between the "four modernizations", the main body composition and business model of farmland management have also changed, which affects the efficiency of land management. Traditional closed rural land management is separated from industrialization and urbanization. Land ownership, contracting rights and the main body of management rights are highly integrated, resulting in a single management model, inactive mechanisms, and low efficiency, which lead that the average rate of return on agricultural land is lower than the average return on social factors. As the "four modernizations" continue to integrate and develop simultaneously, land ownership, contracting rights and management rights have been separated from the three rights. The allocation of capital, technology and talents between urban and rural areas and between workers and farmers has been continuously optimized. Agricultural land management has realized the coordination and unity of multiple subjects, multiple mechanisms and multiple models. The allocation efficiency of land as a scarce resource has improved, and the rate of return gradually approaches until it reaches the average rate of return of the whole society [1].

In this context, experiments on land transfer and scale operations have been launched across the country. Combining land transfer, scale operations with the characteristics of the times, it can give full play to the advantages of the household land contract responsibility system and promote various land reform work to benefit people's livelihood and well-being by going deep into reality and using people's wisdom. Corresponding to the proposal, promotion and implementation of land transfer and land scale, Chinese academic circles have also conducted in-depth research. In just a few years, a large number of research results have been obtained, and it has become one of the 
research hotspots in the field of social sciences. Currently, there are more than 31,318 journal papers on the subject of land scale in the China National Knowledge Internet (CNKI). A large amount of literature provides researchers with rich materials for in-depth research and discussion of land scale, and it also brings challenges for researchers to clearly grasp the overall situation of the field. At present, many scholars have studied the general overview of land transfer and land scale research in detail. Zhang Hongyu analyzed the reasons affecting land transfer and several measures to improve land adjustment [2]. Ma Xiaohe and Cui Hongzhi discussed the problems existing in the land scale in China, and provided new research ideas for constructing a linkage mechanism between land transfer and scale operation [3]. On the whole, the existing literature review focuses on qualitative research, which is not conducive to grasping a large number of existing research results from the macro-structure. In this regard, this article uses CiteSpace visualization to explore the current research status in the field of land transfer and land scale in China, and reveals the research situation in this research field more comprehensively and objectively, so as to carry out more in-depth research and analysis, and provide a new idea for the exploration of frontiers and hot spots in Chinese research fields.

\section{DATA SOURCES AND RESEARCH METHODS}

The evaluation of literature quality and scientific research level of humanities and social sciences mainly depends on the evaluation system of related journals. Chinese universities and research institutions have the highest authority and recognition of the Chinese Social Science Citation Index (CSSCI). The selected documents have high research value and academic level, and can effectively and reliably reflect the frontiers and hot spots of the research field. Therefore, the data in this article comes from CNKI. The journal chooses "CSSCI" to ensure the quality of the paper. The search information includes the title, author of the paper, keywords, author institution, author institution, author's area, journal name, institution name, document type, subject category, and era, etc., which effectively ensures the accuracy of document research. This research uses the advanced search function to search with the keywords "land transfer" and "land scale", the time span is selected from "Unlimited" to 2020, and 150 relevant documents are finally obtained. This article uses CiteSpace to draw a network of authors and institutions for land transfer and scale research, revealing and showing the potential relationship between authors and institutions. And then the researchers draw a collinear network diagram of keywords to objectively and vividly describe the hotspot distribution of research topics.

\section{ANALYSIS OF BIBLIOMETRICS AND KNOWLEDGE GRAPH RESULTS}

\section{A. Distribution of research institutions}

"Table I" shows the co-occurrence network map of research institutions under the visual analysis of CiteSpace. From 2007 to 2020, more than 100 institutions have conducted research on land transfer and land scale operations. "Table I" shows the top eight research institutions in terms of publication volume. Among them, the School of Geospatial Engineering and Science, Sun Yat-sen University, the Research Center for Rural Economy, Ministry of Agriculture and Rural Affairs and the Agricultural Information Institute of CAAS ranked the top three in terms of publication volume.

TABLE I. DISTRIBUTION OF IMPORTANT ACADEMIC INSTITUTIONS UNDER CITESPACE

\begin{tabular}{ccl}
\hline Count & Year & \multicolumn{1}{c}{ Institution } \\
\hline $\mathbf{5}$ & 2007 & $\begin{array}{l}\text { School of Geospatial Engineering and } \\
\text { Science, Sun Yat-sen University }\end{array}$ \\
\hline $\mathbf{4}$ & 2012 & $\begin{array}{l}\text { Research Center for Rural Economy, } \\
\text { Ministry of Agriculture and Rural Affairs }\end{array}$ \\
\hline $\mathbf{3}$ & 2014 & Agricultural Information Institute of CAAS \\
\hline $\mathbf{2}$ & 2009 & School of Economics, Liaoning University \\
\hline $\mathbf{2}$ & 2011 & Sichuan Academy of Social Sciences \\
\hline $\mathbf{2}$ & 2011 & Chinese Academy of Social Sciences \\
\hline $\mathbf{2}$ & 2016 & $\begin{array}{l}\text { College of Economics and Management, } \\
\text { Sichuan Agricultural University }\end{array}$ \\
\hline $\mathbf{2}$ & 2017 & $\begin{array}{l}\text { School of Economics and Management, } \\
\text { North China Agricultural University }\end{array}$ \\
\hline
\end{tabular}

\section{B. Distribution of author power}

There are 150 papers and 115 unique papers, accounting for $77 \%$ of the total literature. The average number of authors per article is 1.01, and the cooperation rate is $23.28 \%$. Price law states that the number of highly productive authors who write half of all papers is equal to the square root of the total number of scientific authors, and the top $12(\sqrt{ } 150 \approx 23)$ are highly productive authors. These 12 highly productive authors published a total of 26 articles, accounting for $17.3 \%$ of the total number of articles. Details are shown in "Table II". 
TABLE II. TOP 10 AUTHORS IN TERMS OF PUBLICATION VOLUME

\begin{tabular}{cll}
\hline $\begin{array}{c}\text { Serial } \\
\text { number }\end{array}$ & \multicolumn{1}{c}{ Author } & $\begin{array}{c}\text { Number of published } \\
\text { articles }\end{array}$ \\
\hline $\boldsymbol{1}$ & Huang Haitang & 3 \\
$\mathbf{2}$ & Wu Lianglin & 3 \\
$\mathbf{3}$ & Zhou Huijie & 2 \\
$\mathbf{4}$ & Ye Weiwu & 2 \\
$\mathbf{5}$ & He Lili & 2 \\
$\mathbf{6}$ & Song Shuqiao & 2 \\
$\mathbf{7}$ & Liu Tao & 2 \\
$\boldsymbol{8}$ & Li Lutang & 2 \\
$\boldsymbol{9}$ & Zhan Lin & 2 \\
$\mathbf{1 0}$ & Bi Xinning & 2 \\
$\boldsymbol{1 1}$ & Dong Xiuru & 2 \\
$\mathbf{1 2}$ & Wang Yanqi & 2 \\
\hline
\end{tabular}

\section{Knowledge map of land scale research over the years}

The keyword is the soul of the paper. Therefore, the analysis of keywords can peek into the research hotspots, knowledge structure and development trends in the field of land transfer and scale. Using the word frequency of the CiteSpace software, the researchers can get the top 15 high-frequency keywords in "Table III" for Chinese land transfer and scale research (see "Table III"). Among them, 65 words appeared in keywords such as " land scale operations", "scale management" and "scale operation", indicating that scholars paid a lot of attention to the land scale. In addition, the occurrence of "land transfer" and "rural land transfer" shows that land transfer is closely related to land scale. The remaining top keywords are rural land, family farm, agricultural mechanization, farmers' income increase, agricultural modernization, etc. Through these high-frequency keywords, it is demonstrated that China's research on land scale and land transfer is strong.

TABLE III. THE TOP 30 HIGH-FREQUENCY KEYWORDS IN THE FIELD OF LAND TRANSFER AND SCALE IN CSSCI PAPERS

\begin{tabular}{clllll}
\hline $\begin{array}{c}\text { Serial } \\
\text { number }\end{array}$ & \multicolumn{1}{c}{ Keywords } & Frequency & $\begin{array}{c}\text { Serial } \\
\text { number }\end{array}$ & Keywords & Frequency \\
\hline $\mathbf{1}$ & Land transfer & 33 & 9 & Land & 9 \\
$\mathbf{2}$ & Land scale operations & 16 & 10 & Rural land transfer & 7 \\
$\mathbf{3}$ & Scale operations & 13 & 11 & Family farm & 6 \\
$\mathbf{4}$ & Scale management & 13 & 12 & Agricultural mechanization & 5 \\
$\mathbf{5}$ & Land scale & 12 & 13 & Farmers' income increase & 5 \\
$\mathbf{6}$ & Land scale management & 11 & 14 & Agricultural modernization & 4 \\
$\mathbf{7}$ & Rural land & 10 & 15 & Countermeasures & 4 \\
\hline
\end{tabular}

"Table III" is a keyword co-occurrence map of land transfer and land scale research. The researchers set the threshold of CiteSpace to 11 and the model size to 85. It can be seen that the entire keyword co-occurrence network is relatively close as a whole. The map presents four major sections with land transfer and scale as the core:

1) Land transfer and the main body of scale operations: It can be seen from the CiteSpace keyword co-occurrence map that farmers, laborers, economic organizations, cooperatives, enterprises, and family farms are all the subjects that scholars pay attention to. Le Zhang [4], Gao Qiang [5] and others used empirical analysis to explain the reasons for the generation of the family farm system, and analyzed related factors such as individuals, families, society, etc. that may affect farmers' willingness to transfer land, and also discussed the impact of land transfer system on scale. Scholars such as Deng Hongtu and Zhao Yan also analyzed the internal logic of the development of Chinese cooperatives to cooperatives from the perspective of enterprises [6].

2) Operation methods and models: Mechanization, land trusteeship, land share purchase, listing and trading, as well as scale operation models such as the household contract responsibility system and family farms have received widespread attention from scholars. Sun Xinhua believed that the scale practice of agricultural services represented by land trusteeship and joint farming and planting can solve the modern contradiction of small-scale farmers' family operations, and can effectively solve the problems of small-scale production reducing efficiency and increasing production costs [7]. Scholars such as Luo Dongqi, Zhu Lifen, etc., based on land transfer and scale, constructed four key operation methods including land conversion, determination of farmers' low-income funds, share setting, and establishment of joint-stock cooperative enterprises [8]. Liu Linghui and Zheng Yaoqun explained the reasons for the infeasibility of large-scale family farms, and proceeded from the benefit-sharing mechanism, power balance mechanism, conflict resolution mechanism construction, and supporting policy mechanisms to build a complete set of mechanisms for realizing moderately large-scale concentration of family farm land to ensure reasonable land transfer and scale operations [9]. 
3) The significance of land transfer and scale operations: Scholars generally believe that the realization of land transfer and scale operations is beneficial to increase farmers' income, improve the efficiency of land resource utilization, deal with the problem of land fragmentation, improve the land system, and promote the development of agricultural industrialization. Scholars such as Mao Peihua, $\mathrm{Xu} \mathrm{Ji}$ and other scholars used the micro-survey data of rural households in 2000 and 2012, and found through empirical analysis that the slow increase in farmers' income is greatly related to the existing land system. On average, land transfer can increase the income of any sample rural households and households that have transferred land by $19 \%$ and $33 \%$, respectively [10]. Scholars such as Han Xudong and Wang Ruonan empirically analyzed that land fragmentation will reduce production efficiency by constructing a stochastic frontier production function, and the current land circulation cannot improve the production efficiency of farmers, because the current land circulation in China is still subject to many restrictions and the real In the sense of scale operation, even aggravated the degree of land fragmentation, thereby further limiting the improvement of agricultural production efficiency [11].

4) Summarizing the land transfer and scale operations in various places: Scholars conducted targeted problem analysis and experience summaries on Yangzhou City, Karst Mountain Area, Daqing City, Lixin County and other regions, and provided reference for the formation of land transfer and scale operations with Chinese characteristics. Scholars such as Jiang Kaisheng and Han Shilai summarized typical cases of land transfer forms such as shareholding, leasing, and transfer in Yangzhou City, Jiangsu Province, and put forward relevant measures to adapt to local conditions and advance in an orderly manner [12]. Scholars such as Liu Hongbin and Dong Xiuru analyzed the status quo and main problems of land scale in the three northeastern provinces, and provided suggestions for realizing land scale from the perspectives of funding channels, labor transfer public policies, land use supervision and management guarantee mechanisms [13].

Through these keyword co-occurrence maps, it is found that Chinese scholars' research on land scale and land transfer has become more abundant since the 20th century, but they are still mainly based on necessity and development mode.

\section{CONCLUSION}

Based on the CiteSpace knowledge map, the article analyzes the knowledge map structure of Chinese land transfer and scale research, and identifies important journals, major research institutions, core author groups and research hotspots for related research, so as to clearly grasp the current research status in the field of Chinese land transfer and scale.

With the continuous development of land transfer, land transfer methods and land scale models have shown a diversified trend. However, academic research on the field of land circulation and scale development still has weak theoretical research guidance, lack of refined research, insufficient innovation and other issues. Research institutions and scholars should grasp the research hotspots and trends of land transfer and scale. On the one hand, it is the improvement of land transfer and scale laws and regulations. As an important resource for the implementation of the "Agriculture, Rural Areas and Farmers" policy, land needs to be well grasped with related supporting policies, which embodies the top-down characteristics from design, implementation to execution. However, the relevant laws and regulations in China are not specific and clear enough and have a lagging nature. In the process of policy implementation, there are often deviations in the grassroots understanding of the policy, resulting in deviations from theoretical logic and practical paths, thereby affecting the effect of land transfer and scale implementation. On the other hand, scholars need to dynamically adjust the research structure of land transfer and scale. Research on land transfer and scale has produced a large number of results, but most of them are concentrated at the micro level, and specific opinions are put forward for each region. Due to regional differences, these experiences are often not of promotional value. However, some macro-level research mainly focuses on policy interpretation, including the connotation, characteristics, and reasons of land transfer and scale, and lacks practical significance. How to conduct meso-level research should be the focus of research institutions and scholars

\section{References}

[1] Wang Yaxin, Research on Rural Land Management Mode Under Four Modernizations Synchronization - Based on the Practice of Zhanjiang, Guangdong [J]. Economic Geography, 2015, 035(008): 157-164. (in Chinese)

[2] Zhang Hongyu, China's Agricultural Land Adjustment and Use Right Circulation: Some Comments [J]. Management World, 2002(05): 76-87. (in Chinese)

[3] Ma Xiaohe, Cui Hongzhi, Establishing a Land Circulation System to Promote Large-scale Operation of Regional Agricultural Production [J]. Management World, 2002(11): 63 77. (in Chinese)

[4] Yue Zhang, The Willingness of Farmers' Land Transaction and Explanation: An Empirical Analysis Based on Survey Data 
from 1032 Farmers in Ten Provinces and Cities [J]. Problems of Agricultural Economy, 2010, 31(02): 64-70+111. (in Chinese)

[5] Gao Qiang, Liu Tongshan, Kong Xiangzhi, System Analysis of Family Farms: Characteristics, Occurrence Mechanism and Effects [J]. Economist, 2013(06): 48-56. (in Chinese)

[6] Deng Hongtu, Zhao Yan, Yang Yun, From Cooperatives to Cooperative Associations: The Economic Logic of Contract Selection Between Leading Enterprises and Farmers under Market Expansion [J]. Management World, 2020, 36(09): 111128. (in Chinese)

[7] Sun Xinhua, Village-led,Peasant Organization and Large-scale Agricultural Service: Analysis on Entrusted Land Management and Joint Farming [J]. Journal of Nanjing Agricultural University (Social Science Edition), 2017, 17(06): 131-140+166. (in Chinese)

[8] Luo Dongqi, Zhu Lifen, Li Yinghui, The Design and Risk Prevention of Rural Land Share Transfer Model from the Perspective of Urban and Rural Planning [J]. Productivity Research, 2009(08): 28-29+3. (in Chinese)

[9] Liu Linghui, Zheng Yaoqun, Study on Realization Mechanism for Family Farm to Get Moderate Scale of Land Concentration [J]. Academic Journal of Zhongzhou, (6): 37-43. (in Chinese)

[10] Mao Peihua, Xu Ji, Farmland System, Land Management Rights Circulation and Farmers' Income Growth [J]. Management World, 2015(05): 63-74+88. (in Chinese)

[11] Han Xudong, Wang Ruonan, Yang Huilian, Zheng Fengtian, Land Fragmentation, Land Transfer and Agricultural Productivity Efficiency: Empirical Analysis Based on 2745 Rural Households Nationwide [J]. Journal of Northwest A\&F University(Social Science Edition), 2020, 20(05): 143-153. (in Chinese)

[12] Jiang Kaisheng, Han Shilai, Chen Dehui, Investigation and Thinking of Land Scale Management in Yangzhou [J]. Macroeconomic Management, 2007(02): 63-65. (in Chinese)

[13] Liu Hongbin, Dong Xiuru, Qian Fengkui, Wang Qiubing, Study on the Scale-up Management of Rural Land: Taking Typical Area of Three Northeast Provinces as Example [J]. China Land Science, 2014, 28(10): 12-19. (in Chinese) 